Review

\title{
Static Osteogenesis versus Dynamic Osteogenesis: A Comparison between Two Different Types of Bone Formation
}

\author{
Marzia Ferretti (D) and Carla Palumbo * (D) \\ Section of Human Morphology, Department of Biomedical, Metabolic and Neural Sciences, University of Modena \\ and Reggio Emilia, Anatomical Institutes, Via del Pozzo 71, 41124 Modena, Italy; marzia.ferretti@unimore.it \\ * Correspondence: carla.palumbo@unimore.it; Tel.: +39-059-4224850
}

Citation: Ferretti, M.; Palumbo, C. Static Osteogenesis versus Dynamic Osteogenesis: A Comparison between Two Different Types of Bone Formation. Appl. Sci. 2021, 11, 2025. https://doi.org/10.3390/app11052025

Academic Editor: Giuseppe Perale

Received: 1 February 2021

Accepted: 20 February 2021

Published: 25 February 2021

Publisher's Note: MDPI stays neutral with regard to jurisdictional claims in published maps and institutional affiliations.

Copyright: (c) 2021 by the authors. Licensee MDPI, Basel, Switzerland. This article is an open access article distributed under the terms and conditions of the Creative Commons Attribution (CC BY) license (https:// creativecommons.org/licenses/by/ $4.0 /)$.

\begin{abstract}
In contrary to what has traditionally been believed, bone formation can occur through two different types of osteogenesis: static (SO) and dynamic (DO) osteogenesis, which are thus named because the former is characterized by pluristratified cords of unexpectedly stationary osteoblasts which differentiate at a fairly constant distance from the blood capillaries and transform into osteocytes without moving from the onset site, while the latter is distinguished by the well-known typical monostratified laminae of movable osteoblasts. The two types of osteogenesis differ in multiple aspects from both structural and functional viewpoints. Besides osteoblast arrangement, polarization, and motion, SO and DO differ in terms of time of occurrence (first SO and later DO), conditioning factors to which they are sensitive (endothelial-derived cytokines or mechanical loading, respectively), distribution of osteocytes to which they give rise (haphazard or ordered in planes, respectively), the collagen texture resulting from the different deposition types (woven or lamellar, respectively), the mechanical properties of the bone they form (poor for SO due to the high cellularity and woven texture and good for DO since osteocytes are located in more suitable conditions to perceive loading), and finally the functions of each, i.e., SO provides a preliminary rigid scaffold on which DO can take place, while DO produces bone tissue according to mechanical/metabolic needs.
\end{abstract}

Keywords: static osteogenesis; dynamic osteogenesis; osteoblasts; osteocytes; intramembranous ossification; endochondral ossification; bone regeneration/healing

\section{Introduction}

It is generally accepted that bone matrix deposition depends on the secretory activity of osteoblasts arranged in monostratified laminae, where all secreting cells are synchronized by side-to-side and gap junctions [1-3] and are polarized towards the same direction, i.e., the osteogenic surface. Moreover, according to the classical view, it is considered that as osteoid seam secretion proceeds, the osteoblastic laminae move away from the osteogenic surface towards the vessels, and those osteoblasts selected to differentiate into osteocytes remain entrapped within the preosseus matrix by the enlargement of their secretory territory (Figure 1) [4]. As a consequence, it has been clearly demonstrated that the rate of osteoblast movement is a function of the V/ST ratio (where $\mathrm{V}$ is the protoplasmic volume and ST is the secretory territory of the osteoblast). In other words, the osteoid appositional growth rate of each osteoblast depends on the proportion of its protoplasm engaged on a given bone surface [5]. In 1999, Marotti and coworkers [6] suggested the term "dynamic osteogenesis" to indicate this well-known type of bone formation (involving osteoblast movement) to distinguish it from another (until then) unknown type of bone deposition discovered for the first time by analyzing intramembranous ossification in detail. This new type of osteogenesis was named "static osteogenesis", because it is performed by stationary osteoblasts that transform into osteocytes at the same site where they differentiate without moving. Later, exhaustive structural and ultrastructural documentation on the morpho-functional differences between these two types of bone formation was provided [7]. 


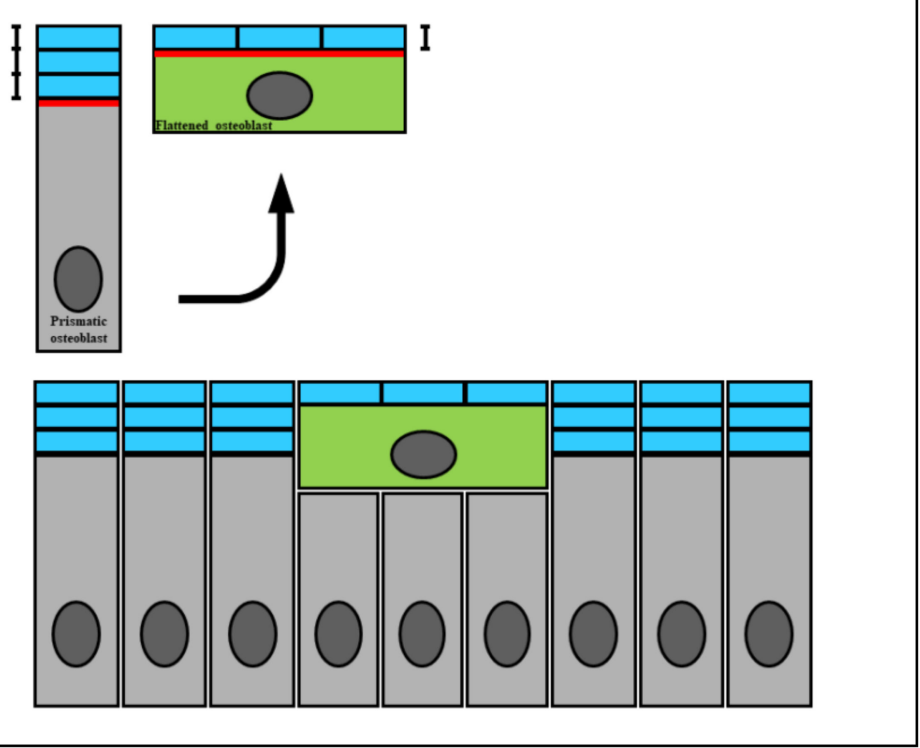

Figure 1. A diagram showing how the wideness of osteoblast secretory territory (red line) varies during its recruitment (green osteoblast), since the produced osteoid seam (blue bars) stratifies on a larger surface according to the morphological modification from a prismatic to a flattened shape. This fact explains the incorporation of recruited osteoblasts transforming into osteocytes (see text for explanation).

In the present review, the two types of osteogenesis, static (SO) and dynamic (DO) osteogenesis, are discussed not only in relation to their time of occurrence and the conditions in which they are performed, but also in relation to their respective morpho-functional significance in both physiological and pathological conditions.

\section{Structural and Functional Differences between SO and DO}

Static and dynamic osteogenesis in various aspects in terms fo their structure, timing, inductive conditioning factors, and meaning. For clarity only we will firstly describe the characteristics of DO (which is classically well known) and then those of $\mathrm{SO}$ (which was only recently discovered), even if, when both occur, they take place in a time sequence (first $\mathrm{SO}$ and then DO).

In particular, with regard to morphology they present consistent differences in: (1) the mobility, arrangement, movement, and polarization of osteoblasts; (2) the morphology and distribution of the resulting osteocytes; and (3) the collagen texture of the bone matrix (Table 1).

In DO, bone deposition occurs by means of monostratified laminae in which prismatic osteoblasts are arranged in epithelial-like manner, all polarized in the same side and sharing the same osteogenic direction, i.e., towards the growing osteogenic surface. As is well known, each osteoblast displays an ill-defined euchromatic nucleus and an organellar machinery which is characteristically highly developed and located in polarized secretory cells. A distinctive feature of osteoblastic laminae during DO is their location in an "asymmetrical" environment, between the mineralized front (from which they move away as they secrete the preosseous matrix) and the vascular surface (towards which they migrate, thus maintaining a favorable metabolic situation) (Figure 2). With regard to the DO osteocyte morphology, there are dendritic elements displaying an almond-like shape in the cell body, in which cytoplasmic processes occur in an asynchronous and asymmetrical manner (first short "mineral-facing" dendrites, then long/slender "vascular-facing" ones) [8] in concomitance with, and depending on, the recruitment in the plane of the "committed" osteoblasts transforming into osteocytes. Such recruitment, in turn, influences the collagen texture, giving rise mostly to lamellar bone. During DO, gap and adherent 
junctions are observed between movable osteoblasts inside the lamina, in addition to gap junctions or simple contacts between osteoblasts and DO osteocyte dendrites as well as between osteocytes in cytoplasmic processes [3].

Table 1. Main morpho-functional differences between SO and DO.

\begin{tabular}{|c|c|c|}
\hline STATIC OSTEOGENESIS & & $\begin{array}{c}\text { DYNAMIC } \\
\text { OSTEOGENESIS }\end{array}$ \\
\hline $\begin{array}{l}\text { at the beginning of the process } \\
\text { of bone formation (fast) }\end{array}$ & TIME OF OCCURRENCE & $\begin{array}{l}\text { soon after the primary thin } \\
\text { SO-trabeculae (slow) }\end{array}$ \\
\hline cytokines issued by vessels & $\begin{array}{l}\text { CONDITIONING } \\
\text { FACTORS }\end{array}$ & $\begin{array}{l}\text { osteocyte signaling (due to } \\
\text { mechanical stress) }\end{array}$ \\
\hline cords & $\begin{array}{l}\text { ARRANGEMENTS OF } \\
\text { OSTEOBLAST }\end{array}$ & monostratified laminae \\
\hline various directions & $\begin{array}{l}\text { POLARIZATION OF } \\
\text { OSTEOBLASTS }\end{array}$ & $\begin{array}{c}\text { same direction (i.e. towards } \\
\text { the pre-existent bone) }\end{array}$ \\
\hline stationary osteoblasts & OSTEOBLAST MOTION & movable osteoblasts \\
\hline $\begin{array}{l}\text { haphazardly, often in } \\
\text { confluent lacunae (high } \\
\text { cellularity) }\end{array}$ & $\begin{array}{l}\text { DISTRIBUTION OF } \\
\text { OSTEOCYTES }\end{array}$ & $\begin{array}{l}\text { orderly manner-the } \\
\text { osteocytes are recruited in } \\
\text { planes (lower cellularity) }\end{array}$ \\
\hline mostly woven bone & TEXTURE & mostly lamellar bone \\
\hline $\begin{array}{l}\text { bad (due to the high } \\
\text { cellularity and woven texture) }\end{array}$ & $\begin{array}{l}\text { MECHANICAL } \\
\text { PROPERTIES }\end{array}$ & $\begin{array}{l}\text { good (osteocytes located in } \\
\text { planes and lamellar texture) } \\
\text {-more suitable to loading }\end{array}$ \\
\hline $\begin{array}{l}\text { to provide a preliminary rigid } \\
\text { scaffold, on which DO } \\
\text { can occur }\end{array}$ & AIMS & $\begin{array}{c}\text { to produce bone tissue } \\
\text { according the } \\
\text { mechanical/metabolic needs }\end{array}$ \\
\hline
\end{tabular}

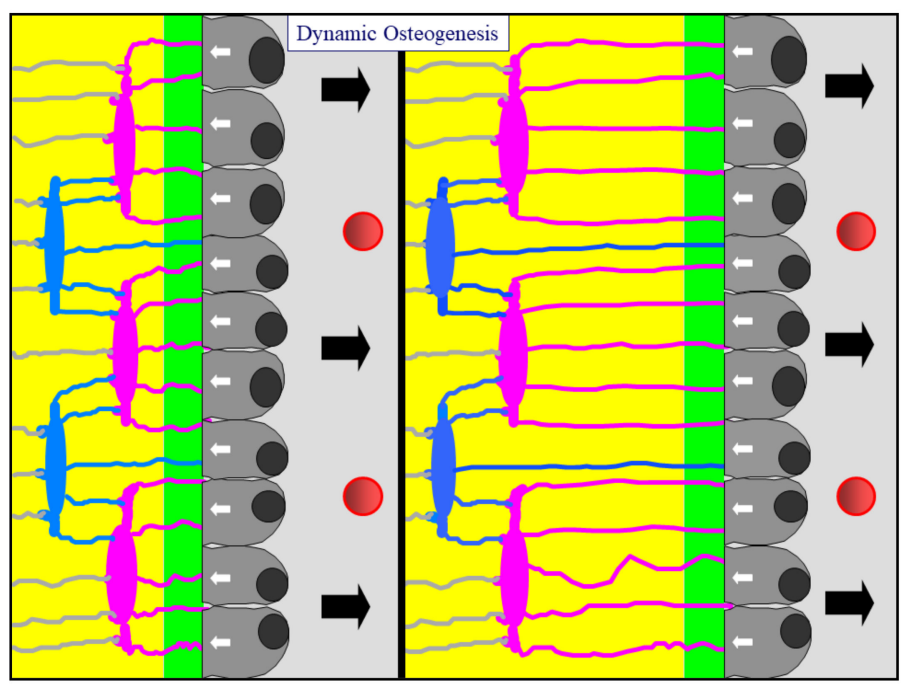

Figure 2. A diagram showing an osteoblastic lamina during DO. From left to right, the osteoblastic lamina moves away (as indicated by black arrows) from the mineralized front (green bar) to the vessels (red circles). The white arrows indicate the osteoblast polarization side. Two generations of almond-like shaped osteocytes (located in planes) are enclosed inside the bone (see text for further details).

In SO, bone deposition occurs by means of unmovable (i.e., stationary) osteoblasts irregularly arranged in cords that differentiate among the vessels (see below); inside the cords, formed by 2-3 layers of cells, osteoblasts are polarized in different directions 
with respect to the adjacent ones, and give rise to osteocytes at the same site where they previously differentiated (Figure 3). A further distinctive feature of these osteoblasts is their presence in a "symmetrical" environment: this differentiates them from those arranged in the typical laminae during DO, which are located in an "asymmetrical" domain (see above). With regard to morphology, SO osteocytes retain approximately the same globous shape and ultrastructure of the parental stationary osteoblasts; moreover, they are often located inside confluent lacunae in the core of the thin bony trabeculae (about 10-15 $\mu \mathrm{m}$ thick), formed only by 2-3 irregular rows/groups of osteocytes. Their dendrites are also shorter than those of DO osteocytes and radiate simultaneously (not in an asynchronous manner as in DO) all around the cell body (Figure 4). At first, the dendrites are so short as to look like spines; afterward, some of them elongate, but only marginally, because their parental osteoblasts are practically stationary, withdrawing from one another by just a few micra. The resulting osteocyte arrangement, which is haphazard and clustered, is dependent on the peculiar recruitment in groups and, in turn, influences the collagen texture, resulting in woven bone (Figure 5). Because the secretory territories of SO stationary osteoblasts are randomly oriented, the matrix is highly porous, and the orientation of the collagen fibers, while uniform at the cellular level [9], is random at larger scales. Gap junctions or simple contacts are observed between stationary osteoblasts and between the spines and dendrites of SO osteocytes [10].

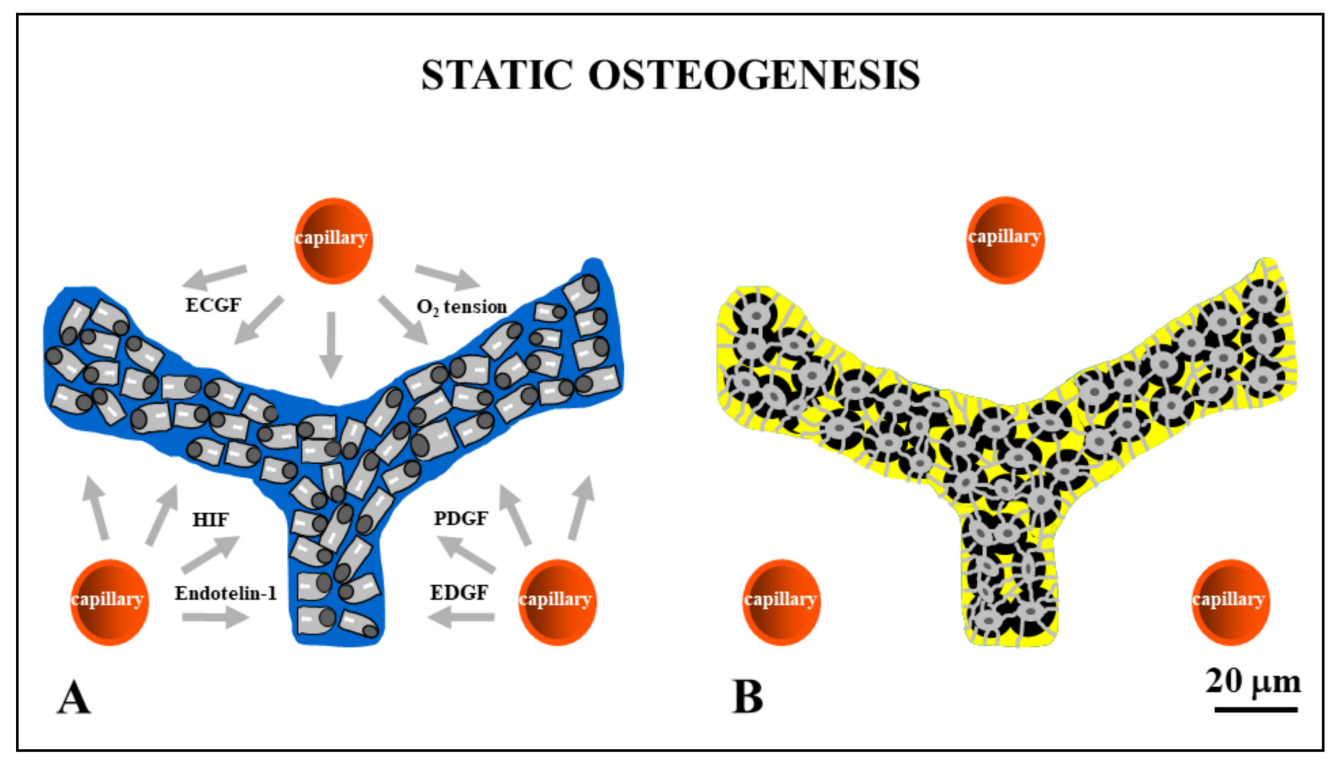

Figure 3. Drawings showing stationary osteoblasts, irregularly arranged in cords, that differentiate among the vessels (red circles). Inside the cords, osteoblasts are polarized in different directions with respect to the adjacent ones (A) and give rise to osteocytes (B) at the same site where they previously differentiated. ECGF: endothelial cell growth factor; HIF: hypoxia-inducible factor; PDGF: platelet-derived growth factor; EDGF: endothelial-derived growth factor.

In addition to the prior differences, $\mathrm{SO}$ and $\mathrm{DO}$ have different conditioning factors. An intriguing problem is the differentiation of stationary osteoblasts at a certain distance from the vessels; SO allows the formation of a preliminary trabecular bony framework enclosing the blood vessels. This is essential for the subsequent bone apposition by DO. In a previous paper of ours [11], when comparing intramembranous and endochondral ossifications, the following crucial differences between SO and DO clearly emerged. During intramembranous ossification center development, bone growth occurs by progressive extension of stationary osteoblastic cords inside the surrounding mesenchyme, fairly constantly at about midway between blood capillaries (mean distance of cords from vessels, $28 \pm 0.4 \mu \mathrm{m}$ ). Recently, in a study on regeneration with bone substitutes, the intimate functional connection between blood vessels and bone formation highlighted the combined interaction between the mesenchymal stem cell secretome (extracellular vesicles) and microRNAs [12]. How- 
ever, this fact does not explain the mechanism by which mesenchymal cells (transforming into preosteoblasts) "sense" the position of the vessels. Several factors may be involved, such as $\mathrm{O}_{2}$ tension [13,14], endothelial cell-derived cytokines (i.e., endothelin-1) [15-17], and growth factors (EDGF, ECGF) [18-21]. In particular, vascular endothelial growth factor (VEGF), a main player in angiogenesis, is capable of provoking the migration and proliferation of endothelial cells and indirectly stimulating osteogenesis through the regulation of the osteogenic growth factors released through paracrine signaling [12]. Moreover, in studies on bone healing, it was shown that osteoblast differentiation could also depend on platelet-derived growth factor (PDGF) [22-24]. In a study concerning genetic manipulations in mice, Schipani and coworkers [25] recently highlighted the critical role of the hypoxia-inducible-factor/vascular endothelial growth factor (HIF) pathway in coupling angiogenesis and osteogenesis.

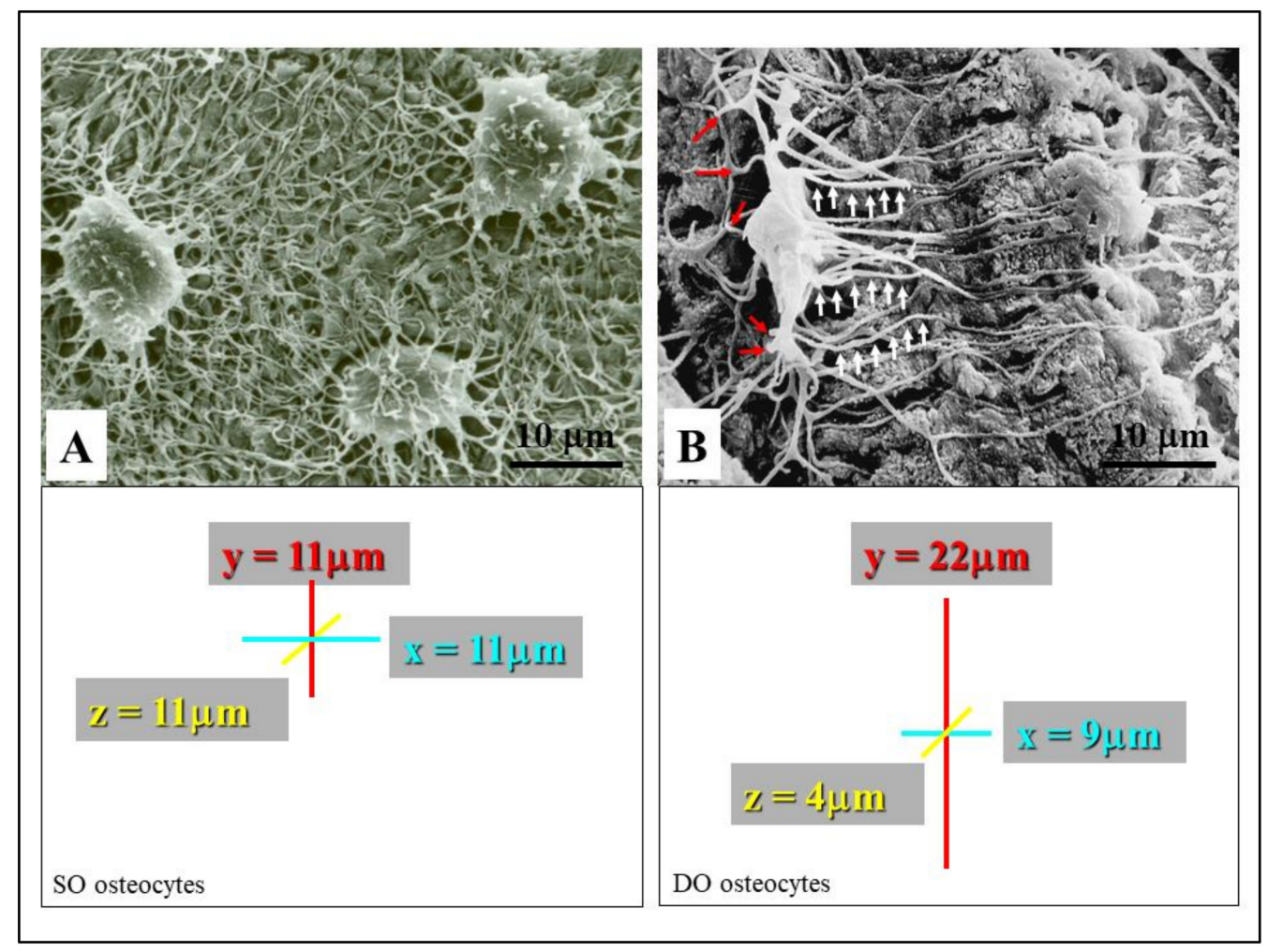

Figure 4. SEM micrographs showing the morphology of SO/DO osteocytes. (A) SO osteocytes have a globous shape, and their short dendrites radiate all around the cell body. (B) DO osteocytes display an almond-like shaped cell body and two different types of cytoplasmic processes: the short "mineral-facing" dendrites (red arrows) and the long/slender "vascular-facing" dendrites (white arrows). The square areas show the mean values of osteocyte cell body axes; the almost spherical morphology of SO osteocytes with respect to the triaxial ellipsoidal shape of the DO osteocytes can be seen.

Briefly, SO is triggered by inductive stimuli. Since during $\mathrm{SO}$ the bone matrix is laid down without preexistent osteocytes, we believe that the irregular arrangement and polarization of the osteoblasts in stationary osteogenic cords probably depends on a lack of osteocyte guidance. Only after SO, does DO occurs by means of movable osteoblastic laminae. These $\mathrm{DO}$ osteoblasts are likely guided by $\mathrm{SO}$ osteocytes (inside the preliminary SO bony trabeculae) and are also capable of "sensing" the vessels (towards which they move) through the stromal cells located between the migrating laminae of the bone-growing surfaces and the vascular endothelia [26].

To summarize, $\mathrm{SO}$ is in fact a form of neo-osteogenesis, in the sense that it occurs in mesenchymal tissue (for example during intramembranous ossification of the cranial vault) in which pre-existing bone is lacking and therefore there are no osteocytes that can act as 
mechanosensors to guide the subsequent osteogenesis. In tissues where SO occurs, the absence of mechano-sensors makes mechanical stresses completely irrelevant since they cannot be perceived. It follows that the $\mathrm{SO}$ can only be induced by cytokines released by the endothelial cells; it is therefore to be considered a typical process of osseoinduction which is mechanically independent.

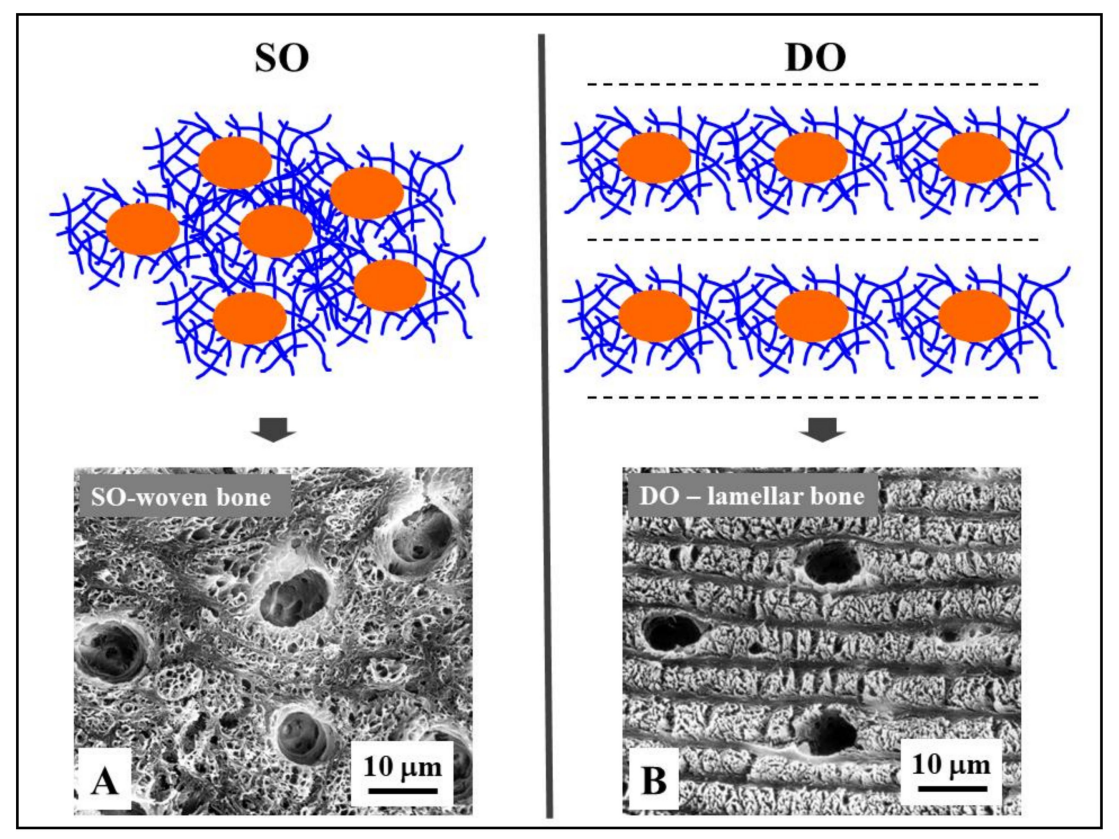

Figure 5. Osteocyte arrangements in static and dynamic osteogenesis (top): Osteocytes (orange) are always found within a pericellular loose collagen texture (blue) in both SO (osteocytes arranged in group) and DO (osteocytes recruited on a plane). Depending on the cell arrangement, woven bone texture forms in SO, while lamellar bone forms in DO. (bottom) SEM micrographs (A, B) of osteocyte lacunae in SO (right) and DO (left).

Conversely, DO occurs on the surfaces of a pre-existing bone containing osteocytes (Figure 6), which perceive the deformations induced in the bone matrix by mechanical loading. Therefore, in DO mechanical factors can play a pivotal role in triggering and directing the activity of osteoblasts (Figure 7). It is thus to be considered a process of osseoconduction which is strongly influenced by mechanical stress [27].

Besides the described differences, $\mathrm{SO}$ and $\mathrm{DO}$ also occur with diverse speeds: in $\mathrm{SO}$, bone matrix is generally produced very rapidly, while in DO the events proceed over a longer period of time. Thus, the former allows for the formation of a preliminary network of trabecular woven bone (surrounding wide primitive vascular spaces), which has a supporting function for subsequent lamellar bone apposition by typical movable osteoblasts (Figure 8); this in turn allows SO trabeculae thickening by DO and consequently the narrowing of the primitive vascular haversian spaces, giving rise to primary osteons (i.e., bone compaction) (Figure 9).

In this regard, it should be underlined that SO and DO also differ in the involvement of the apoptosis occurring adjacent to the sites of osteogenesis: this is more frequently observed during DO than during SO, because in this context apoptosis is mainly dedicated to making space for advancing bone osteogenesis. This is in line with the progression modes of the two processes, because DO is an invasive process involving the invasion of mesenchyme, filling the primary haversian spaces, while SO proceeds following a non-invasive pattern [28].

Osteocytes derived by both static and dynamic osteogenesis remain in contact with each other by gap junctions, forming a functional syncytium (i.e., a network of strainsensitive cells throughout the developing bone tissue) which also stays in contact with 
the osteoblasts covering the bone growth surfaces $[7,10]$ (Figure 10). It is of note that the stationary osteoblasts allow for the "introduction" of the strain-sensitive osteocytes capable of sensing and responding to mechanical signals from the inception of bone formation.

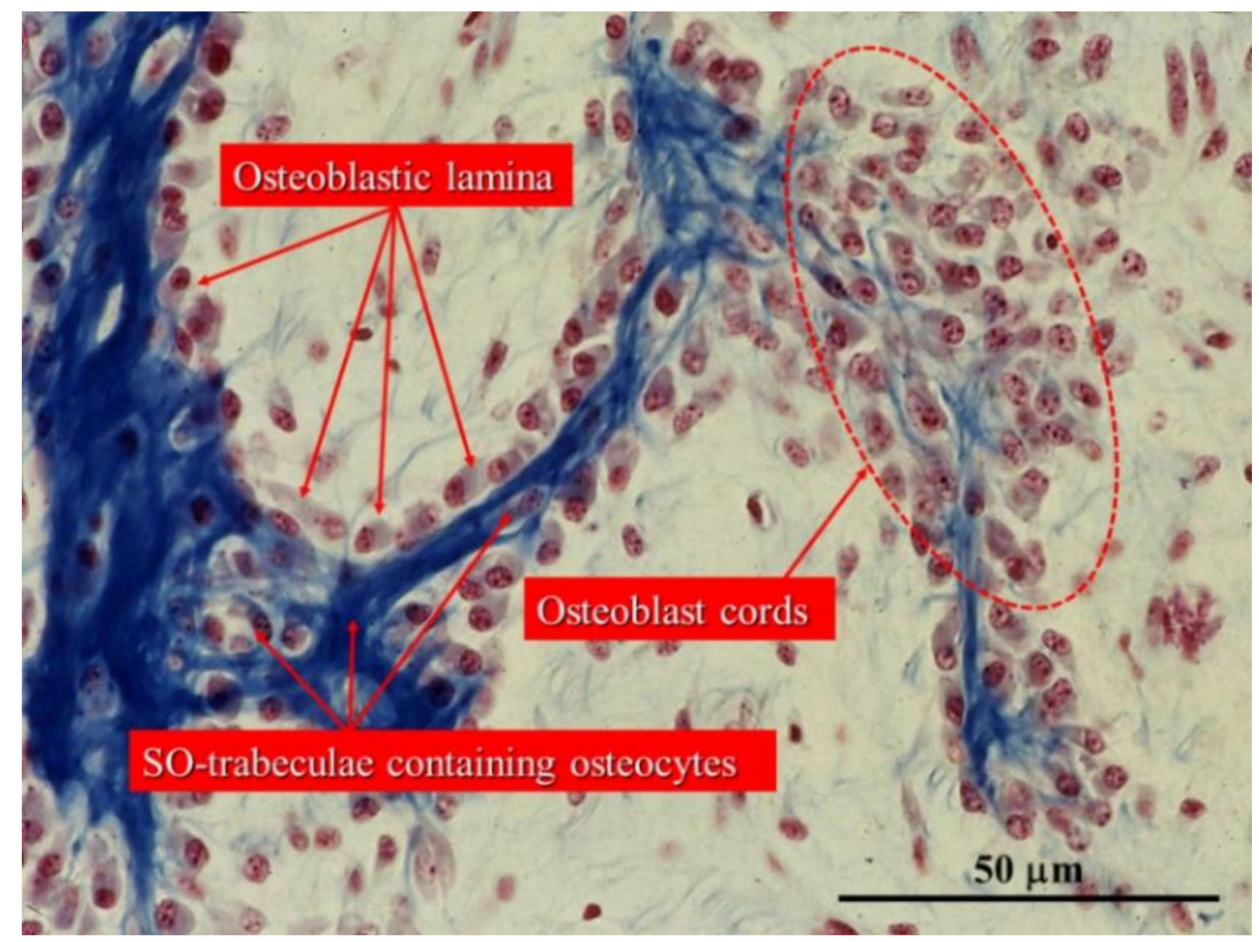

Figure 6. Histological section of an intramembranous ossification center showing a cord of stationary osteoblasts (red circles) and osteoblastic laminae on the surfaces of pre-existing bone containing SO osteocytes. (Light microscope photo from new-born rabbit calvaria).

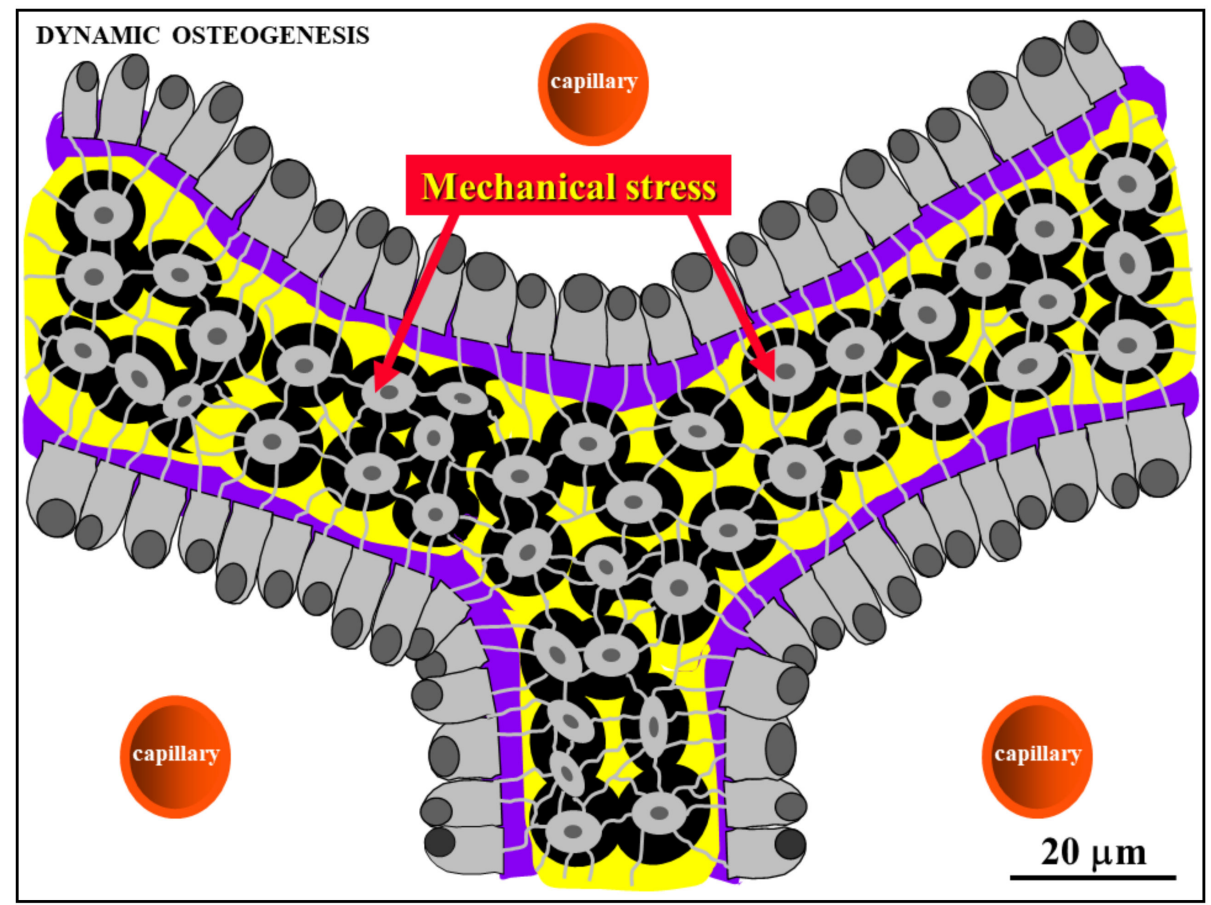

Figure 7. Schematic drawing showing laminae of movable osteoblasts laying down bone matrix (purple) on the surfaces of SO trabeculae (see text for further explanation). 


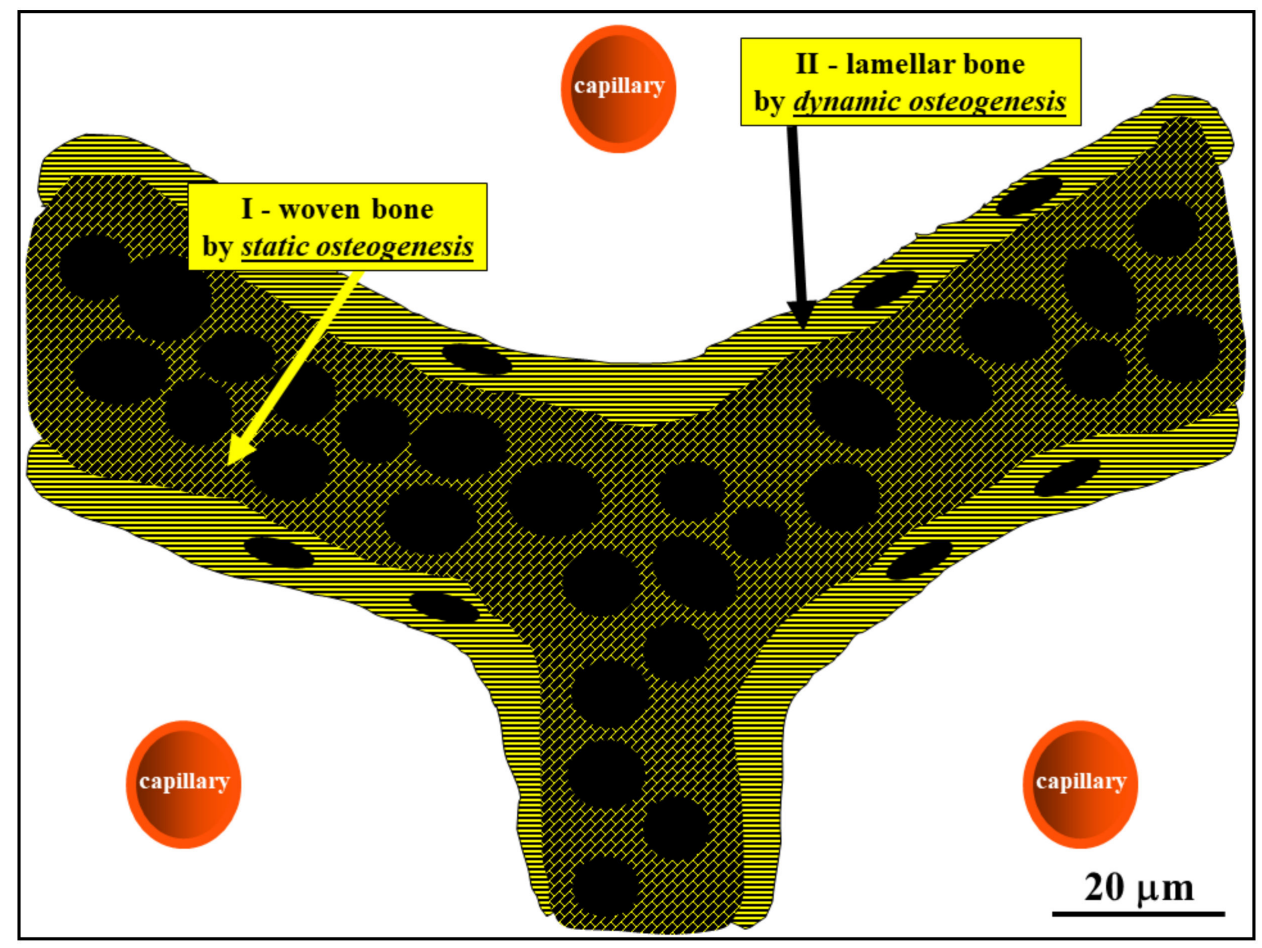

Figure 8. Schematic drawing showing the woven bone (by SO) forming the core of preliminary trabeculae for successive lamellar bone apposition by typical movable osteoblasts (in DO). (See SEM micrographs in Figure 5).

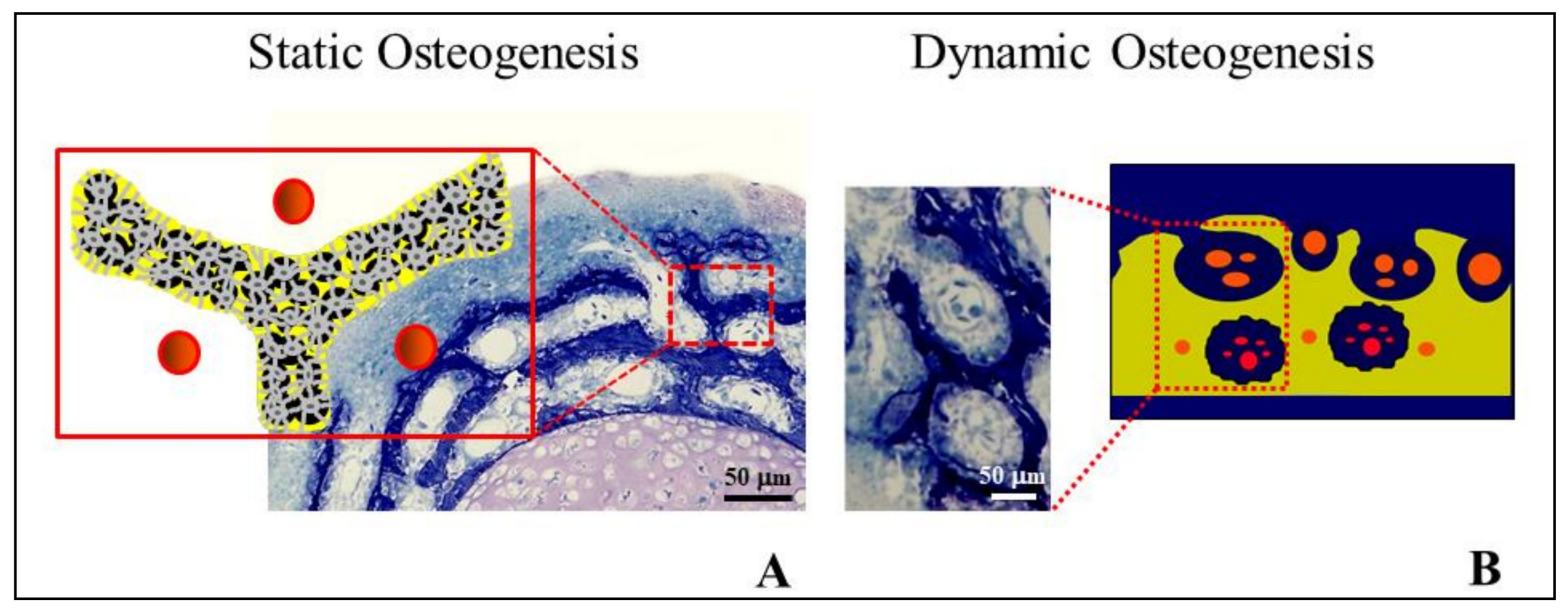

Figure 9. Cross-sections at the mid shaft level of the cartilaginous bud of a chick embryo showing: (A) SO trabeculae surrounding primary haversian spaces (the schematic drawing depicted in the insert represents the field of the square area in the histological section); (B) primitive vascular haversian spaces narrowed by means of DO (i.e., bone compaction), thickening SO trabeculae and giving rise to primary osteons (the histological section shows the field in the square in the schematic drawing).

In contrast to intramembranous ossification, $\mathrm{SO}$ never takes place during endochondral ossification [11]. In this case, DO occurs directly close to the remnants of calcifying cartilage; in fact, the remnants of calcifying cartilage have the same supporting function of the preliminary trabeculae in SO forming at the onset of intramembranous ossification (Figure 11). 


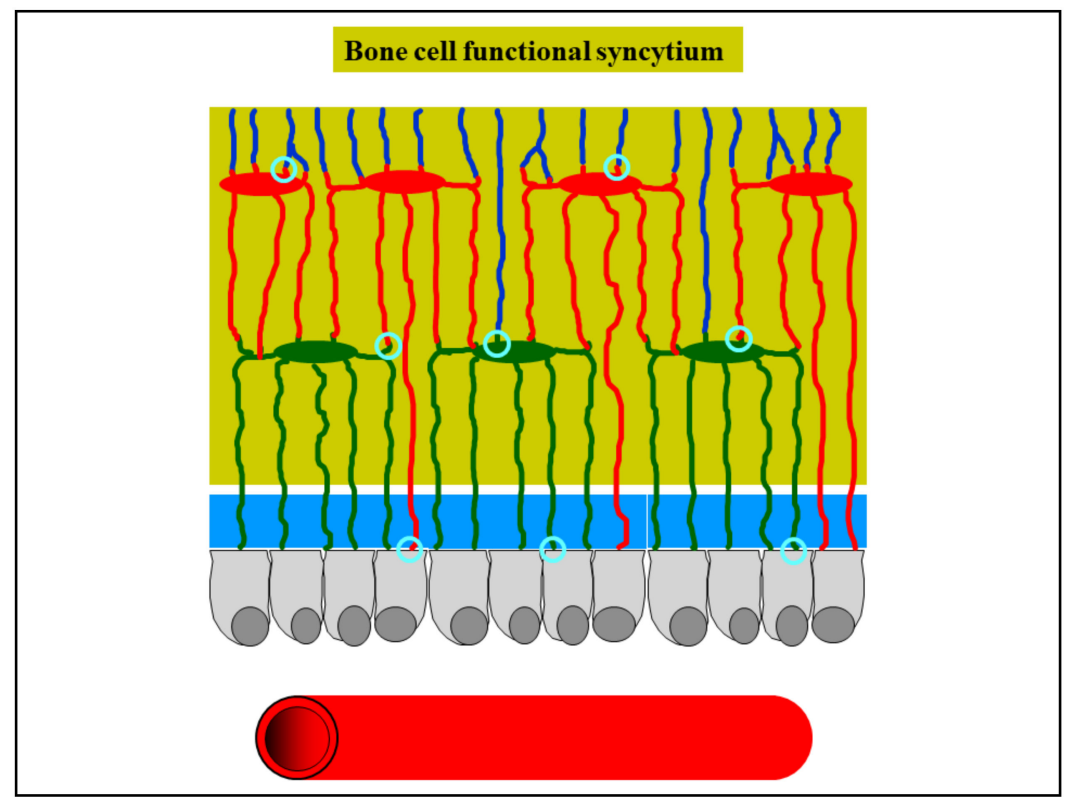

Figure 10. Schematic drawing showing osteocytes remaining in contact with each other by gap junctions (light blue circles), forming a functional syncytium which also stays in contact with the osteoblasts covering the bone growth surfaces (see text for further explanation).
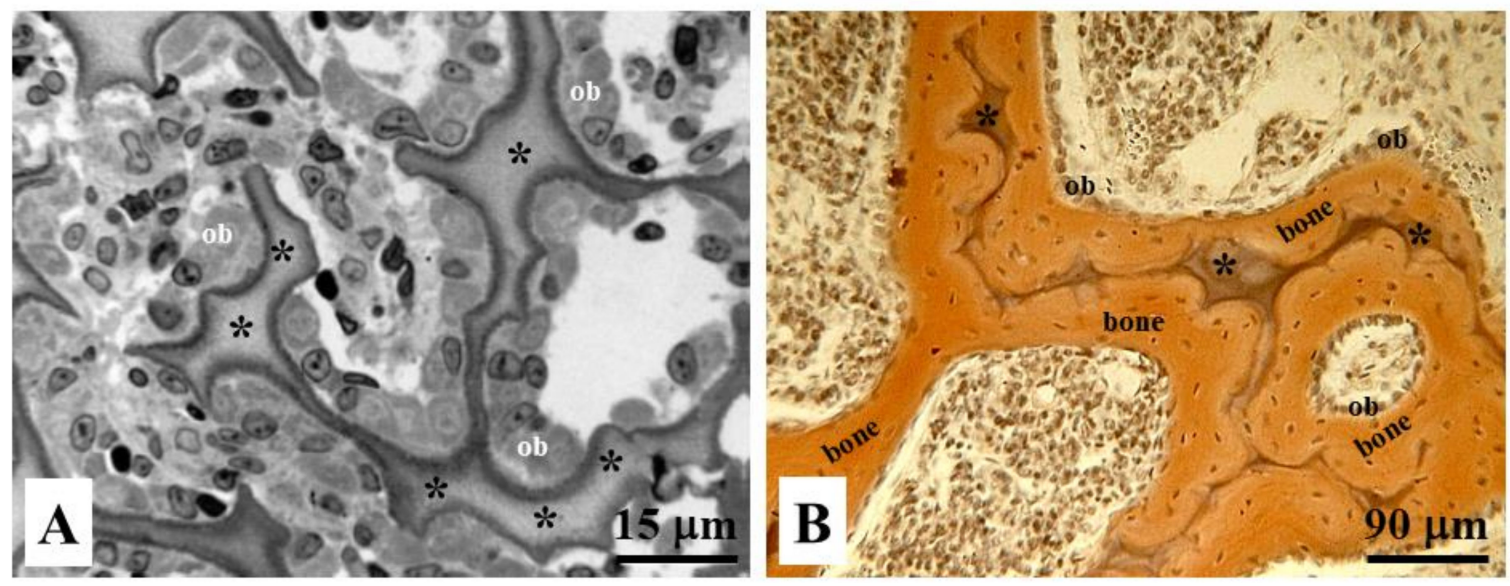

Figure 11. Histological sections of endochondral ossification in (A) osteoblastic laminae (ob) differentiated close to the remnants of calcified cartilage (asterisks), and in (B) bone deposition occurring through movable osteoblastic laminae forming and then compacting the primary haversian systems by dynamic osteogenesis.

\section{SO Versus DO during Ontogeny and the Origin of Bone Tissue Diversity}

Several authors have discussed the importance of static versus dynamic osteogenesis during ontogenesis in studies on lower vertebrates and phylogenetically distant organisms as well as in bone healing.

Traini [29] showed that during both bone healing of alveolar cavities after dental extraction and during peri-implant bone remodeling the pattern of jaw deposition retraces the ontogenetic steps that normally occur during its formation. In a model of hamster fetuses, the author [29] showed that alveolar bone formation occurs by static osteogenesis (SO), while the basal bone facing the Meckel's cartilage is deposited by dynamic osteogenesis (DO), in line with our evidence. Moreover, again in line with our results, the author reported that in human alveolar cavities the healing processes take place at the onset by SO and the thickness of the newly formed SO trabeculae by DO increases 
only after 4 weeks, allowing for successive remodeling processes. Traini's results [29] provided further evidence that $\mathrm{SO}$ is a process that is not only related to skeletal formation in membranous ossification but also occurs in the initial healing phase of the alveolar wound with the ability to quickly fill space; subsequently, the bone mass increases through DO. Confirming what we have highlighted about the collagen texture resulting from the two different types of osteogenesis, Traini [29] reported that in the initial phase, SO creates a trabecular bone framework of woven bone, followed by DO, which increases the size of the trabeculae by lamellar bone deposition. With dental implants, the author later showed that the remodeling process occurred only by DO both in compact and trabecular bone.

Similar aspects were emphasized by Stein and Prondvai [30] and by Prondvai et al. [31], who underlined functional and evolutionary considerations for SO and DO in proposing a new classification of bone tissues. In fact, based solely on the distinction between tissues derived from the two different types of osteogenesis they suggested the following classification: woven bone tissue (SO-derived), parallel-fibered bone tissue (DO-derived), and complex (i.e., composite) bone tissue resulting from combined SO and DO processes. Moreover, Stein and Prondvai [30] underlined that: (1) the combination of SO-controlled rapid volume expansion and $\mathrm{DO}$-controlled bone compaction characterizes the different phases of active growth; and (2) the functional relationships between the two types of osteogenesis are not only crucial at the onset of axial skeletal organogenesis, but also later, as for example in determining the diametrical growth rate of the limbs.

Cubo and coworkers [32] tested whether the ontogenetic sequence of bone formation (suggested, in lower vertebrates, by Ferretti et al. [7], Palumbo et al. [10], and Marotti et al. [33]) is homologous and acquired also by the last common ancestor of amniotes. Cubo's group [32] studied the developmental patterns of some amphibians and reptiles (pertaining to outgroups of amniotes and ectothermic amniotes), analyzing the results obtained in the context of tetrapod phylogeny. In the context of the commonly accepted tetrapod phylogeny, using the parsimony method the authors [32] concluded that (1) the ontogenetic sequence observed in chickens and in rabbits, according to which SO precedes DO, is convergent, and (2) the ontogenetic pattern observed in Pleurodeles larvae and Pogona embryos, according to which SO does not precede DO, corresponds to the plesiomorphic condition for both Tetrapoda and Amniota. This evidence is reflected in the different bone architectures between growing small amphibians/squamates and growing mammals/birds. Cubo and coworkers [34] tested the hypothesis suggested by Palumbo et al. [10], according to which "without preexisting osteocytes only woven bone can form (through SO), because an orderly recruitment of osteocytes can only take place by signals issued by a preexisting osteocyte syncytium". At the onset of bone formation, the presence of a cohort of stationary osteoblasts is necessary, independently of whether static or dynamic osteogenesis is taking place; without such stationary osteoblasts, the first layers of bone tissue would not contain osteocytes. The authors [34] also affirmed that, in Pleurodeles and Pogona, DO occurs even without a rigid mineralized framework, whereas in chick embryos and newborn rabbits it seems to take place over a mineralized support in bone (as observed in perichondral ossification by Ferretti et al. [7] and by Palumbo et al. [10]) or calcified cartilage (as observed in endochondral ossification by Ferretti et al. [11]). Cubo and coworkers [34] also explained that in the bone collar (i.e., the thick vascularized bone tissue layer surrounding the cartilaginous shaft) further maturation of pre-osteoblasts is controlled by either SO or DO processes. As SO starts to take place, randomly oriented mesenchymal cells condensate into 1-3-cell-thick layers halfway between the adjacent capillaries of the bone collar and start to differentiate into stationary osteoblasts. At the same time, in other regions of the periosteum DO-controlled osteoblasts are organized into osteogenic laminae. While static osteoblasts produce the first thin trabeculae of porous irregularly fibered woven bone between the capillaries, the DO-derived osteogenic laminae start to deposit highly organized bone matrix on already existing surfaces like the forming SO-derived trabeculae or the limb precursor. Since the SO-derived woven framework incorporates large vascular spaces into the bony substance within a short period of time, rapid 
diametrical growth can be realized by means of rapid volume expansion of the forming limb bone shaft. SO osteoblasts start to mineralize their secreted matrix very early, filling it up with apatite crystallites. After the sauropod embryo develops the diametrical expansion in parallel to compaction of the developing limb bone (performed by SO and DO processes, respectively), the successive active growth phases of postembryonic ontogeny continue in time in the same way. As DO proceeds and compacts the primary vascular spaces, at some point the osteogenic lamina may start to form lamellae around the progressively narrowing vascular space.

\section{Experimental Evidence for SO and DO Occurrence}

The occurrence of SO and DO explains varied evidence both in experimental conditions and in pathological situations.

In one of our experimental studies [35] concerning the timing and manner of bone healing in rat femurs (after drilling transcortical holes, with/without contemporary administration of parathyroid hormone, PTH (1-34)), the interpretation of the results clearly underlined the correlation with the sequential occurrence of the two types of osteogenesis. The final goal was to identify the phase of osteogenesis (static versus dynamic) in which PTH (1-34) can most significantly exert its eventual effect, in order to determine how and when to use the drug with maximum efficacy in improving bone lesion repair strategies. Histomorphometric analysis revealed that 10 days after drilling, despite the holes being temporarily filled by the same amount of newly formed trabecular bone by static osteogenesis independent of the treatment, the extent of the surface of movable osteoblast laminae (covering the SO-trabecular surface) was statistically greater in animals which underwent PTH (1-34) administration as compared to controls. This datum strongly suggests the effect of PTH (1-34) in anticipating the occurrence of dynamic osteogenesis involved in the production of good-quality bone (i.e., lamellar bone, with a more ordered collagen texture, instead of woven-fibered bone) more suitable for mechanical loading. With regard to the translational aspect of basic research, the authors wanted to stress the importance of the two types of osteogenesis in the clinical research to define the best therapeutic approaches/strategies for drug use in orthopedics for recovery from severe skeletal lesions.

The two types of osteogenesis were found to be crucial in data interpretation in two of our (successive) investigations [36,37] for determining whether PTH (1-34) administration during normal diet restoration (after a calcium-free diet) can influence the amounts and sites of bone mass recovery. Besides the importance of the interplay between mineral homeostasis and skeletal homeostasis in modulating and guiding bone response to dietary/metabolic alterations, evidence emerged that the most-involved bony architecture is trabecular bone, as it is the most susceptible to the dynamical balance between the two types of homeostasis. Trabecular bone has the ability to respond more readily to mineral homeostasis. This ability of trabecular bone led to: (1) higher bone loss of less-loaded bony trabeculae as a consequence of a calcium-free diet in response to mineral homeostasis, and (2) new bone deposition on the surface of the few remaining overloaded trabeculae by means of dynamic (instead of static) osteogenesis to respond to skeletal homeostasis during normal diet restoration. Once again, the kind of osteogenesis recruited in bone healing is not irrelevant.

On the contrary, in some pathologies like human facet joint osteoarthritis (FJOA), remodeling of the subchondral trabecular bone compartment is characterized by increased trabecular number, rather than trabecular thickening [38]; this observation can be explained by the impairment of viability of osteocytes (i.e., the bone mechanosensors) inside the trabecular bone due to osteoarthritis, where static (as compared to dynamic) osteogenesis underpins specific bone remodeling and is activated through the recruitment of osteoprogenitor cells by endothelial-derived growth factors, giving rise to the formation of new trabeculae. The same authors also commented that a histological analysis of osteocyte lacunae in healthy and osteoarthritic specimens could provide further support for the role of static osteogenesis in the pathogenesis of FJOA. 
Another pathology where static and dynamic osteogenesis explains some evidence is osteogenesis imperfecta (OI), as described by Shapiro et al. in 2020 [39]. The terms "static" and "dynamic" osteogenesis correspond to the definitions previously reported by Shapiro [40], i.e., with regard to the differences in osteoblast location/function in "mesenchymal osteoblasts" (MOBLs) that produce woven bone and "surface osteoblasts" (SOBLs) that produce lamellar bone. After the production of woven bone by MOBLs, SOBLs continued to secrete lamellar bone close to the woven scaffold. Shapiro and coworkers [39] observed in OI that "the more severe the variant of OI is, the greater the persistence of woven bone and the more immature the structural pattern; the pattern shifts to a structurally stronger lamellar arrangement once a threshold accumulation for an adequate scaffold of woven bone has been reached". The authors correlated SO and DO with the subsequent temporal phases of woven (first) and lamellar (later) bone deposition by MOBLs and SOBLs, respectively, in the production of normal/healed/pathological bone. Lamellar bone organization increases as the disease resolves. In OI, the hypercellularity of bone depends on the relatively reduced matrix synthesis; however, the woven and lamellar bone segments are hypercellular to differing extents both in relation to each other and to normal bone. This is mainly due to woven bone rather than lamellar bone (which contains fewer cells as compared to normal woven bone).

During bone healing induced by dental bone implants and in biomaterial osseointegration [33], SO and DO are crucial for evaluating the fate of implanted materials (Figure 12). In fact, the same sequence of events occurs as during intramembranous ossification in skeletal organogenesis, with firstly SO (depending on inductive stimuli) and then DO (which is mechanically driven). As a consequence of the different levels of quality of the derived bone tissue texture (poor in SO and mechanically valid in DO), the clinical implications of these findings are related to the time of load application after prosthesis/biomaterial implantation. This fact is empirically applied in the clinical practice of both orthopedic and maxillo-facial surgeons. For this reason, it is crucial to determine the timing of the transition between SO and DO in post-surgical and implant behavior in order to establish when poor-quality bone can be loaded after reinforcement/replacement with bone actually capable of resisting mechanical loading has taken place.

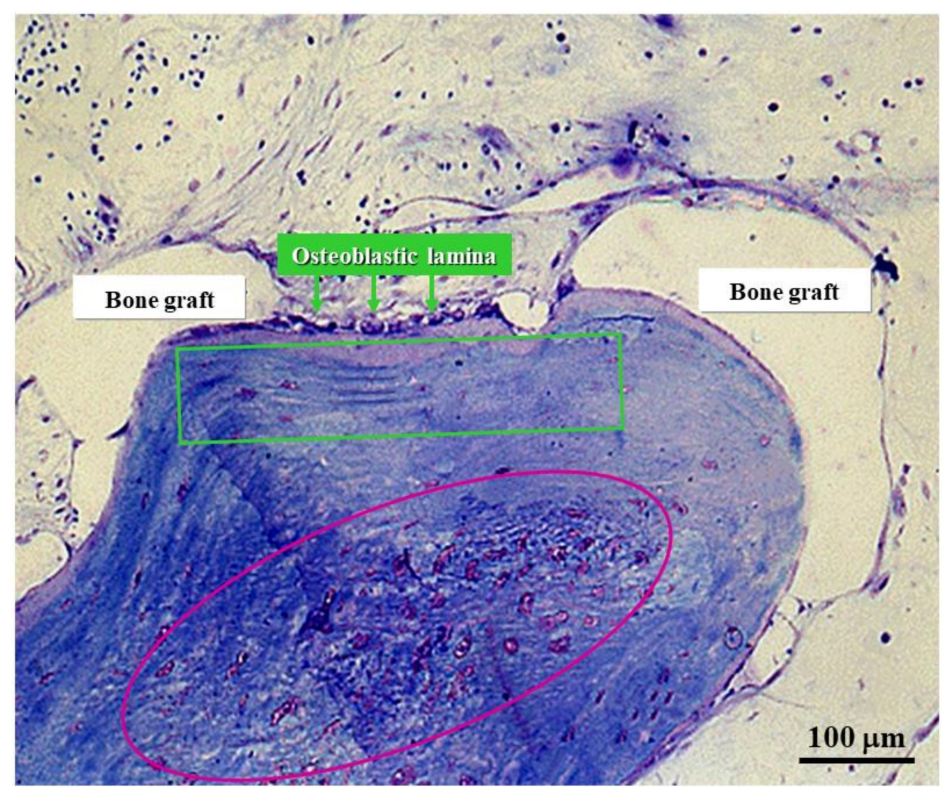

Figure 12. Micrograph under LM in ordinary light showing graft osseointegration. The purple circle outlines the core of a SO trabecula made up of woven bone containing many globous osteocytes. The green square outlines the lamellar bone subsequently laid down by DO. 
The aspects concerning inductive/mechanical stimuli and bone texture quality also acquire particular importance during healing of cranial linear osteotomies with different devices; this has been experimentally induced in rabbits to test the validity of traditional procedures versus piezosurgery [41,42]: the observations with regard to bone gap healing are in line with our previous observations [7] on the steps occurring in a sequence during bone histogenesis.

\section{OD Versus OS in Relation to Non-Osteogenic Cells}

It is known that osteogenic cells, besides being engaged in bone formation in response to metabolic and mechanical demands, are also involved in bone resorption. This is because osteoclast formation/activation also depends on the relationships between hemopoietic precursors and the osteoblast cell lineage which promote osteoclast formation from precursors through the production of macrophage-colony stimulating factor (M-CSF) and receptor activator nuclear factor $\mathrm{Kb}$-ligand (RANKL) [43]. Likewise, osteoclastic lineage cells are also influential in the processes of osteogenesis; indeed, osteoclasts not only resorb bone but also provide signals to promote bone formation. This is particularly true during the bone remodeling cycle, whereby after the first phase (resorption) [44,45], in the second phase (reversion) the cells of the reversal phase (of stromal/fibroblast origin) differentiate into osteoblasts. With regard to the course of this phase, the pathways which allow the coupling between bone resorption and the successive osteogenesis (third phase) are not yet well known, but various authors believe that reversal phase cells could be involved in sending or receiving signals [46-48]. It has also been suggested that osteoclasts alone may be the source of coupling factors by means of secreting cytokines or via regulatory receptors and their membrane-bound ligands [49]. Thus, after indirect osteoclast-osteoblast coupling, osteogenesis can occur (third phase). As far as osteoclast-osteoblast coupling is concerned, Sims and Martin in 2020 [50] reported that osteoclasts act on osteoblastic lineage cells during their differentiation, facilitating the release of growth factors from the resorbed matrix and producing secreted proteins and microvesicles, as well as expressing membrane-bound factors. These different mechanisms mediate the coupling of bone resorption to bone formation. Further interactions of osteoclasts with the osteogenic lineage cells (via the cells of the reversal phase) are necessary to achieve coordination between the two processes, i.e., bone resorption and osteogenesis. The possible role of osteoclasts in osteoblast induction is also corroborated by the evidence that in a hematological malignancy (i.e., multiple myeloma), the plasma cell accumulation into the bone marrow leads to bone destruction due to severely unbalanced and uncoupled bone remodeling; indeed, an increase in osteoclast enrollment/activity, together with deep osteoblast suppression, has been shown in multiple myeloma patients [51,52]. Moreover, in multiple myeloma, the interaction between cancer cells and bone stromal cells also inhibits the activity of Runx2, the main pro-osteoblastogenic transcription factor, leading to the suppression of osteoblast differentiation [53].

In this context, it is to be emphasized that only DO is functionally correlated to the suggested role of osteoclasts in triggering osteoblast recruitment via reversal phase cells, since the third-phase osteogenesis of bone remodeling cycle is only performed by DO. The fact that SO never occurs close preexistent bone (with static osteogenesis being the first to appear where no bone exists previously) underlines how the differentiation of stationary osteoblast cords is not at all related to conditioning by osteoclasts. This is another substantial difference between DO and SO.

\section{Conclusions and Future Perspectives}

In conclusion, the morpho-functional aspects of SO and DO, which have been wellinvestigated during both skeletal organogenesis and bone regeneration, could acquire particular relevance in clinical practice as far as their translational significance is concerned.

As previously reported, in bone healing the first stages of bone deposition produce poor-quality bone due to inductive stimuli so that loading appears to be useless or some- 
times even dangerous during static osteogenesis; on the contrary, mechanical loading, which is known to greatly enhance osteoblast activity, becomes very important after the onset of dynamic osteogenesis. Therefore, it could become crucial in clinical practice to determine for how long $\mathrm{SO}$ continues before DO starts, primarily to establish when poorquality bone is reinforced with (or replaced by) bone which is actually capable of resisting mechanical loading (Figure 13). At the moment, functional investigations are in progress to better elucidate the transition time and manner from SO to DO.

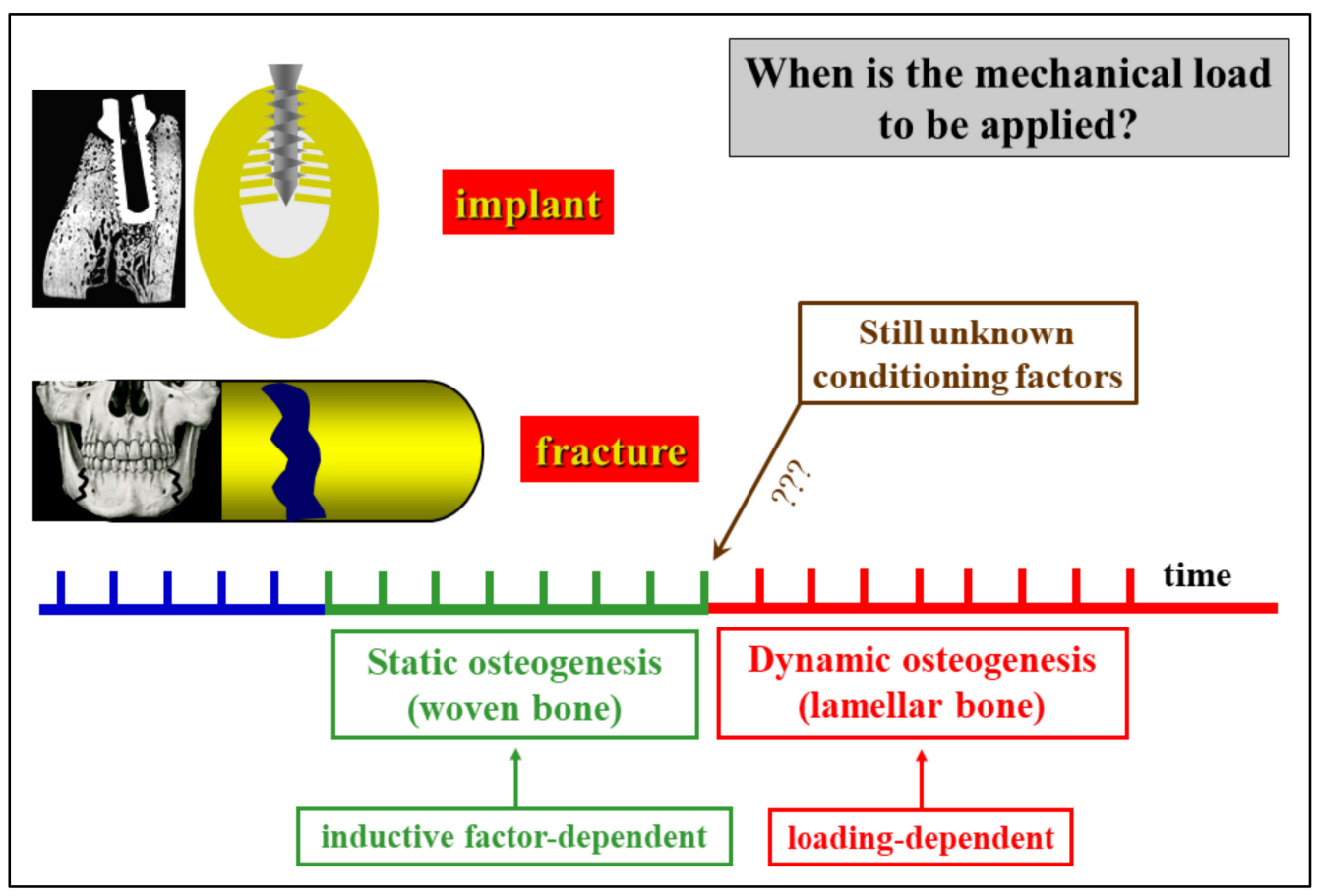

Figure 13. Schematic drawing with regard to the translational meaning of SO versus DO (see text for explanation).

A key aspect to be clarified in the near future is the duration time, in different conditions, of $\mathrm{SO}$ before the initiation of $\mathrm{DO}$, for instance during critical-size bone defect healing, biomaterial/prosthetic osseo-integration, and bone loss recovery after severe metabolic pathologies.

Author Contributions: Both authors conceptualized, wrote, and agreed to the published version of the manuscript. Both authors have read and agreed to the published version of the manuscript.

Funding: This research received no external funding.

Informed Consent Statement: Not applicable.

Data Availability Statement: Data contained within the review are available in the papers cited in the section References.

Acknowledgments: The authors thank Marta Benincasa for her valuable help in setting iconography.

Conflicts of Interest: The authors declare no conflict of interest.

\section{References}

1. Jeansonne, B.G.; Feafin, F.F.; McMinn, R.W.; Scoemaker, R.L.; Rehm, V.S. Cell-to-cell comunication of osteoblasts. J. Dent. Res. 1979, 58, 1415-1423. [CrossRef] [PubMed]

2. Doty, S.B. Morphological evidence of gap junctions between bone cells. Calcif. Tissue Int. 1981, 33, 509-512. [CrossRef]

3. Palumbo, C.; Palazzini, S.; Marotti, G. Morphological study of intercellular junctions during osteocyte differentiation. Bone 1990, 11, 401-406. [CrossRef]

4. Marotti, G.; Ferretti, M.; Muglia, M.A.; Palumbo, C.; Palazzini, S. A quantitative evaluation of osteoblast-osteocyte relationships on growing endosteal surface of rabbit tibiae. Bone 1992, 13, 363-368. [CrossRef] 
5. Marotti, G. Decrement in volume of osteoblasts during osteon formation and its effects on the size of the corresponding osteocytes. In Bone Histomorphometry; Meunier, P.J., Ed.; Armour Montagu: Paris, France, 1976; pp. 385-397.

6. Marotti, G.; Ferretti, M.; Palumbo, C.; Benincasa, M. Static and dynamic bone formation and the mechanism of collagen fiber orientation. Bone 1999, 25, 156.

7. Ferretti, M.; Palumbo, C.; Contri, M.; Marotti, G. Static and dynamic osteogenesis: Two different types of bone formation. Anat. Embryol. 2002, 206, 21-29. [CrossRef]

8. Palumbo, C.; Palazzini, S.; Zaffe, D.; Marotti, G. Osteocyte differentiation in the tibia of newborn rabbit: An ultrastructural study of the formation of cytoplasmic processes. Acta Anat. 1990, 137, 350-358. [CrossRef]

9. Kerschnitzki, M.; Wagermaier, W.; Roschger, P.; Seto, J.; Shahar, R.; Duda, G.N.; Mundlos, S.; Fratzl, P. The organization of the osteocyte network mirrors the extracellular matrix orientation in bone. J. Struct. Biol. 2011, 173, 303-311. [CrossRef] [PubMed]

10. Palumbo, C.; Ferretti, M.; Marotti, G. Osteocyte dendrogenesis in static and dynamic bone formation: An ultrastructural study. Anat. Rec. A 2004, 278, 474-480. [CrossRef]

11. Ferretti, M.; Palumbo, C.; Bertoni, L.; Cavani, F.; Marotti, G. Does static precede dynamic osteogenesis in endochondral ossification as occurs in intramembranous ossification? Anat. Rec. A 2006, 288A, 1158-1162. [CrossRef]

12. Diomede, F.; Marconi, G.D.; Fonticoli, L.; Pizzicanella, J.; Merciaro, I.; Bramanti, P.; Mazzon, E.; Trubiani, O. Functional Relationship between Osteogenesis and Angiogenesis in Tissue Regeneration. Int. J. Mol. Sci. 2020, 21, 3242. [CrossRef] [PubMed]

13. Brighton, C.T.; Schaffer, J.L.; Shapiro, D.B.; Tang, J.J.; Clark, C.C. Proliferation and macromolecular synthesis by rat calvarial bone cells grown in various oxygen tensions. J. Orthop. Res. 1991, 9, 847-854. [CrossRef] [PubMed]

14. Lennon, D.P.; Edmison, J.M.; Caplan, A.I. Cultivation of rat marrow-derived mesenchimal stem cells in reduced oxygen tension: Effects on in vitro and in vivo osteochondrogenesis. J. Cell Physiol. 2001, 187, 345-355. [CrossRef]

15. Sasaki, T.; Hong, M.H. Endothelin-1 localization in bone cells and vascular endothelial cells in bone marrow. Anat. Rec. 1993, 237, 332-337. [CrossRef]

16. Kasperk, C.H.; Borcsok, I.; Schairer, H.U.; Schneider, U.; Nawroth, P.P.; Niethard, F.U.; Ziegler, R. Endothelin-1 is a potent regulator of human bone cell metabolism in vitro. Calcif. Tissue Int. 1997, 60, 368-374. [CrossRef] [PubMed]

17. Inoue, A.; Kamiya, A.; Ishiji, A.; Hiruma, Y.; Hirose, S.; Hagiwara, H. Vasoactive peptide-regulated gene expression during osteoblastic differentiation. J. Cardiovasc. Pharmacol. 2000, 365 Suppl. 1, S286-S289. [CrossRef]

18. Guenther, H.L.; Fleisch, H.; Sorgente, N. Endothelial cells in culture synthesize a potent bone cell active mitogen. Endocrinology 1986, 119, 193-201. [CrossRef] [PubMed]

19. Canalis, E.; McCarthy, T.; Centrella, M. The regulation of bone formation by local growth factors. In Bone and Mineral Research; Peck, W.A., Ed.; Elsevier: Amsterdam, The Netherlands, 1989; Volume 6, pp. 27-56.

20. Streeten, E.A.; Brandi, M.L. Biology of the bone endothelial cells. Bone Miner. 1990, 10, 85-94. [CrossRef]

21. Villanueva, J.E.; Nimni, M.E. Promotion of calvarial cell osteogenesis by endothelial cells. J. Bone Min. Res. 1990, 5, 733-739. [CrossRef]

22. Zheng, M.H.; Wood, D.J.; Papadimitriou, J.M. What's new in the role of cytokines on osteoblast proliferation and differentiation? Phatol. Res. Pract. 1992, 188, 1104-1121. [CrossRef]

23. Lind, M. Growth factor stimulation of bone healing. Effects on osteoblasts, osteomies, andimpiants fixation. Acta Orthop. Scand. 1998, 283, 2-37.

24. Chaudhary, L.R.; Hofmeister, A.M.; Hruska, K.A. Differential growth factor control of bone formation through osteoprogenitor differentiation. Bone 2004, 34, 402-411. [CrossRef]

25. Schipani, E.; Maes, C.; Carmeliet, G.; Semenza, G.L. Perspective Regulation of osteogenesis-angiogenesis coupling by HIFs and VEGF. J. Bone Min. Res. 2009, 24, 1347-1353. [CrossRef] [PubMed]

26. Palazzini, S.; Palumbo, C.; Ferretti, M.; Marotti, G. Stromal cell structure and relationships in perimedullary spaces of chick embryo shaft bones. Anat. Embryol. 1998, 197, 349-357. [CrossRef]

27. Marotti, G. Static and Dynamic osteogenesis in the processes on bone repair. G.I.O.T. 2004, 30 (Suppl. 1), 1-5.

28. Palumbo, C.; Ferretti, M.; De Pol, A. Apoptosis during intramembranous ossification. J. Anat. 2003, 203, 589-598. [CrossRef] [PubMed]

29. Traini, T. The development of the alveolar bone by static osteogenesis: Microanatomy and clinical implications. J. Oral Surg. 2013, 4, 29-37.

30. Stein, K.; Prondvai, E. Rethinking the nature of fibrolamellar bone: An integrative biological revision of sauropod plexiform bone formation. Biol. Rev. 2014, 89, 24-47. [CrossRef] [PubMed]

31. Prondvai, E.; Stein, K.H.W.; De Ricqlès, A.; Cubo, J. Development-based revision of bone tissue classification: The importance of semantics for science. Biol. J. Linn. Soc. Lond. 2014, 112, 799-816. [CrossRef]

32. Cubo, J.; Hui, M.; Clarac, F.; Quilhac, A. Static osteogenesis does not precede dynamic osteogenesis in periosteal ossification of Pleurodeles (Caudata, Amphibia) and Pogona (Squamata, Lepidosauria). J. Morphol. 2017, 278, 621-628. [CrossRef] [PubMed]

33. Marotti, G.; Zaffe, D.; Ferretti, M.; Palumbo, C. Static osteogenesis and dynamic osteogenesis: Their relevance in dental bone implants and biomaterial osseointegration. JOB 2010, 1, 133-139.

34. Cubo, J.; Legendre, P.; de Ricqles, A.; Montes, L.; de Margerie, E.; Castanet, J.; Desdevises, Y. Phylogenetic, functional, and structural components of variation in bone growth rate of amniotes. Evol. Dev. 2008, 10, 217-227. [CrossRef] 
35. Cavani, F.; Ferretti, M.; Smargiassi, A.; Palumbo, C. PTH(1-34) effects on repairing experimentally drilled holes in rat femur: Novel aspects-Qualitative vs. quantitative improvement of osteogenesis. J. Anat. 2017, 230, 75-84. [CrossRef]

36. Ferretti, M.; Cavani, F.; Smargiassi, A.; Roli, L.; Palumbo, C. Mineral and Skeletal Homeostasis Influence the Manner of Bone Loss in Metabolic Osteoporosis due to Calcium-Deprived Diet in Different Sites of Rat Vertebra and Femur. Biomed. Res. Int. 2015, 304178. [CrossRef]

37. Ferretti, M.; Cavani, F.; Roli, L.; Checchi, M.; Magarò, M.S.; Bertacchini, J.; Palumbo, C. Interplay among calcium diet content, $\mathrm{PTH}(1-34)$ treatment and balance of bone homeostases in rat model: The trabecular bone as keystone. Int. J. Mol. Sci. 2019, 20, 753. [CrossRef] [PubMed]

38. Netzer, C.; Distel, P.; Wolfram, U.; Deyhle, H.; Jost, G.F.; Schären, S.; Geurts, J. Comparative Analysis of Bone Structural Parameters Reveals Subchondral Cortical Plate Resorption and Increased Trabecular Bone Remodeling in Human Facet Joint Osteoarthritis. Int. J. Mol. Sci. 2018, 19, 845. [CrossRef] [PubMed]

39. Shapiro, F.; Maguire, K.; Swami, S.; Zhu, H.; Flynn, E.; Wang, J.; Wu, J.Y. Histopathology of osteogenesis imperfecta bone. Supramolecular assessment of cells and matrices in the context of woven and lamellar bone formation using light, polarization and ultrastructural microscopy. Bone Rep. 2020. PII: S2352-187230494-0. [CrossRef]

40. Shapiro, F. Bone development and its relation to fracture repair. The role of mesenchymal osteoblasts and surface osteoblasts. Eur. Cells Mater. 2008, 15, 53-76. [CrossRef] [PubMed]

41. Anesi, A.; Ferretti, M.; Cavani, F.; Salvatori, R.; Bianchi, M.; Russo, A.; Chiarini, L.; Palumbo, C. Structural and ultrastructural analyses of bone regeneration in rabbit cranial osteotomy: Piezosurgery versus traditional osteotomes. J. Cranio Maxillofac. Surg. 2018, 46, 107-118. [CrossRef] [PubMed]

42. Anesi, A.; Di Bartolomeo, M.; Pellacani, A.; Ferretti, M.; Cavani, F.; Salvatori, R.; Nocini, R.; Palumbo, C.; Chiarini, L. Bone Healing Evaluation Following Different Osteotomic Techniques in Animal Models: A Suitable Method for Clinical Insights. Appl. Sci. 2020, 10, 7165. [CrossRef]

43. Suda, T.; Takahashi, N.; Udagawa, N.; Jimi, E.; Gillespie, M.T.; Martin, T.J. Modulation of osteoclast differentiation and function by the new members of the tumor necrosis factor receptor and ligand families. Endocr. Rev. 1999, 20, 345-357. [CrossRef] [PubMed]

44. Palumbo, C.; Ferretti, M.; Ardizzoni, A.; Zaffe, D.; Marotti, G. Osteocyte-osteoclast morphological relationships and the putative role of osteocytes in bone remodeling. J. Musculoskel. Neuron. Interact. 2001, 1, 327-332.

45. Toscani, D.; Bolzoni, M.; Ferretti, M.; Palumbo, C.; Giuliani, N. Role of osteocytes in myeloma bone disease: Anti-sclerostin antibody as new therapeutic strategy. Front. Immunol. 2018, 9, 2467. [CrossRef]

46. Delaisse, J.M. The reversal phase of the bone-remodeling cycle: Cellular prerequisites for coupling resorption and formation. Bonekey Rep. 2014, 3, 561. [CrossRef] [PubMed]

47. Everts, V.; Delaissé, J.M.; Korper, W.; Jansen, D.C.; Tigchelaar-Gutter, W.; Saftig, P.; Beertsen, W. The bone lining cell: Its role in cleaning Howship's lacunae and initiating bone formation. J. Bone Miner. Res. 2002, 17, 77-90. [CrossRef] [PubMed]

48. Raggatt, L.J.; Partridge, N.C. Cellular and molecular mechanisms of bone remodeling. J. Biol. Chem. 2010, 285, 25103-25108. [CrossRef] [PubMed]

49. Zhao, C.; Irie, N.; Takada, Y.; Shimoda, K.; Miyamoto, T.; Nishiwaki, T.; Suda, T.; Matsuo, K. Bidirectional ephrinB2-EphB4 signaling controls bone homeostasis. Cell Metab. 2006, 4, 111-121. [CrossRef]

50. Sims, N.A.; Martin, T.J. Osteoclasts provide coupling signals to osteoblast lineage cells through multiple mechanisms. Annu. Rev. Physiol. 2020, 82, 507-529. [CrossRef]

51. Roodman, G.D. Pathogenesis of myeloma bone disease. Leukemia 2009, 23, 435-441. [CrossRef]

52. Yaccoby, S. Advances in the understanding of myeloma bone disease and tumour growth. Br. J. Haematol. 2010, 149, 311-321. [CrossRef] [PubMed]

53. Giuliani, N.; Colla, S.; Morandi, F.; Lazzaretti, M.; Sala, R.; Bonomini, S.; Grano, M.; Colucci, S.; Svaldi, M.; Rizzoli, V. Myeloma cells block RUNX2/CBFA1 activity in human bone marrow osteoblast progenitors and inhibit osteoblast formation and differentiation. Blood 2005, 106, 2472-2483. [CrossRef] [PubMed] 